\title{
Fine structure of the eggs of blowflies Aldrichina grahami and Chrysomya pacifica (Diptera: Calliphoridae)
}

\author{
KOM SUKONTASON ${ }^{1}$, KABKAEW L. SUKONTASON ${ }^{1}$, SOMSAK PIANGJAI $^{1}$, \\ WEJ CHOOCHOTE ${ }^{1}$, NOPPAWAN BOONCHU ${ }^{1}$, TARINEE CHAIWONG ${ }^{1}$, and \\ HIROMU KURAHASHI ${ }^{2}$
}

\footnotetext{
${ }^{1}$ Department of Parasitology, Faculty of Medicine, Chiang Mai University, Chiang Mai 50200, Thailand. ${ }^{2}$ Department of Medical Entomology, National Institute of Infectious Diseases, Tokyo 162-8640, Japan.
}

\begin{abstract}
We report here the fine structure of the eggs of blowflies Aldrichina grahami (Aldrich) and Chrysomya pacifica Kurahashi. For A. grahami, the plastron is wide and extends to almost the entire length of the eggs. The plastron near the micropyle is truncated. The polygonal patterns of chorionic sculpture bear a distinct swollen boundary. Regarding $C$. pacifica, the plastron is narrow and extends to almost the entire length of the eggs. The plastron near the micropyle bifurcates to a Y-shape, but the arms of the ' $\mathrm{Y}$ ' are short. Information presented herein allows some distinctive features to differentiate among eggs of blowfly species.
\end{abstract}

Blowflies are medically important, and their larvae have occasionally been reported as the cause of myiasis in humans and animals (Zumpt, 1965). Today, however they are more important in the area of forensics. Blowfly specimens (eggs, larvae, or pupae) collected in human corpses are being used as entomological evidence in forensic investigations not only to estimate the postmortem interval, but also to analyze any toxic substance involved in the cause of death (e.g., Smith, 1986; Lord, 1990; Goff, 2000; Greenberg and Kunich, 2002).

Identification of fly specimens collected from a corpse is primarily needed for use in forensic investigations. The blowfly eggs of many genera are of forensic importance and have been studied using scanning electron microscopy (SEM) in many parts of the world (Kitching, 1976; Greenberg and Szyska, 1984; Erzinclioğlu, 1989; Liu and Greenberg, 1989; Greenberg and Singh, 1995; Greenberg and Kunich, 2002). We describe herein, the eggs of two species of blowflies [Aldrichina grahami (Aldrich) and Chrysomya pacifica Kurahashi] which had not been previously investigated, to provide a greater database for blowfly identification. In view of medical importance, A. grahami was a forensically relevant species, due to its presence in pig carcasses (Ma et al., 1997). Chrysomya pacifica was previously identified as Chrysomya megacephala (Fabricius), and it was recently separated as $C$. pacifica, and therefore its biological information is very limited. However, the other blowflies in genus Chrysomya, particularly C. megacephala and Chrysomya rufifacies (Macquart), are well known for forensic importance. Chrysomya pacifica may be involved in forensic entomology in the future.

The preserved eggs of $A$. grahami (laboratory-bred Japanese strain) and $C$. pacifica (laboratory-bred strain from Papua New Guinea) were used in this study. For 
SEM, the eggs were initially washed several times using normal saline solution to remove any attached debris. The specimens were fixed with $2.5 \%$ glutaraldehyde mixed in phosphate buffer solution (PBS) at a pH of 7.4 at $4{ }^{\circ} \mathrm{C}$ for 24 $\mathrm{hr}$. They were then rinsed twice with PBS at 10-min intervals. The rinsed eggs were then treated with $1 \%$ osmium tetroxide at room temperature for $3 \mathrm{hr}$ for post-fixation. This was followed by rinsing the eggs twice with PBS and dehydrating them with alcohol. To replace water in the eggs with alcohol, the eggs were subjected to increasing concentrations of alcohol as follows: $30 \%$, $50 \%, 70 \%, 80 \%$ and $90 \%$. The eggs remained in each concentration of alcohol for $12 \mathrm{hr}$ during each step of the dehydration process. They were then placed in absolute alcohol for two $12 \mathrm{hr}$ periods followed by acetone for two $12 \mathrm{hr}$ periods. Finally, the eggs were subjected to critical point drying to complete the dehydration process. In order to view the eggs, they were first attached with double-stick tape to aluminum stubs so they could be coated with gold in a sputter-coating apparatus before being viewed with a JEOL-JSM840A scanning electron. Terminology of the fly eggshell followed Margaritis (1985).

Blowfly eggs are creamy-white, elongated, and taper at the ends. The eggs of A. grahami are $1.38 \pm 0.07 \mathrm{~mm}$ in length and $0.36 \pm 0.06 \mathrm{~mm}$ in width $(n=50)$. The plastron is wide $(0.029 \pm 0.011 \mathrm{~mm}$ in width) and upright (Fig. 1A, star in Fig. 1C) and extends to almost the entire length of the eggs (Fig. 1A). The plastron near the micropyle is truncated, but does not apparently bifurcate (arrow, Fig. 1B). The polygonal patterns of chorionic sculpture bear a distinct swollen boundary (arrow, Fig. 1C). Regarding $C$. pacifica, the eggs are $1.54 \pm 0.14 \mathrm{~mm}$ in length, and $0.37 \pm$ $0.07 \mathrm{~mm}$ in width $(n=50)$. The plastron is narrow $(0.009 \pm 0.003 \mathrm{~mm}$ in width $)$, and extends almost the entire length of the eggs (Fig. 2A). The plastron near the micropyle bifurcates to a Y-shape, but the arms of the ' $Y$ ' are short (arrow, Fig. 2B). The hatching line along the plastron area is smooth and swollen (star, Fig. 2C). The polygonal lines are faint (arrow, Fig. 2C).
Regarding eggs of A. grahami, the wide and upright plastron are similar to those of blowfly species such as Phaenicia (=Lucilia) caeruleiviridis (Macquart), Phaenicia (=Lucilia) illustris (Meigen), and Lucilia cuprina (Wiedemann) (Greenberg and Kunich, 2002). The swelling at the polygonal pattern boundary of A. grahami resembles the blowfly egg of Calliphora alpina (Žetterstedt) (Erzinclioglu, 1989), but is markedly different from the faint boundary of $L$. cuprina (Sukontason, unpublished data of author). Thus, the information presented here allows some distinctive features to differentiate among eggs of calliphorine and luciliine blowfly species.

Medically, A. grahami has been claimed to be a necrophagous insect since the larvae usually feed on putrid animal matter (Shinonaga, 1965). Furthermore, fly specimens of this species have also been found in pig carcass, the animal model in forensic entomology experiments conducted in both indoor and outdoor areas in Hangzhou, Zhejiang, China (Ma et al., 1997). This could point to A. grahami as the forensically relevant fly species. Kurahashi and Chowanadisai (2001) noted that the adult fly is attracted to decaying matter in towns located $>1,000 \mathrm{~m}$ above sea level in north Vietnam, but it is also very common in the lowlands of Japan (Kurahashi et al., 1984). This species is widely distributed, as it exists in Russia (East Siberia, Far East), Japan, Korea, China, Hong Kong, Indonesia, Philippines, India, Taiwan, North Vietnam, Pakistan, Australia, and has been accidentally introduced into the USA (California and Hawaii) (Hall, 1948; Hardy, 1981).

Although $C$. pacifica is morphologically similar to the Oriental Latrine Fly $C$. megacephala, it is currently classified as a separate species by one of the authors $(\mathrm{H}$. Kurahashi). The fine egg structure of $C$. pacifica in this study provided more evidence to separate the two species. The $\mathrm{Y}$-shape of the plastron near the micropyle of $C$. pacifica has a short arm (arrow, Fig. 2B), while that of $C$. megacephala is relatively long (Kitching, 1976; Greenberg and Kunich, 2002). However, the narrow 

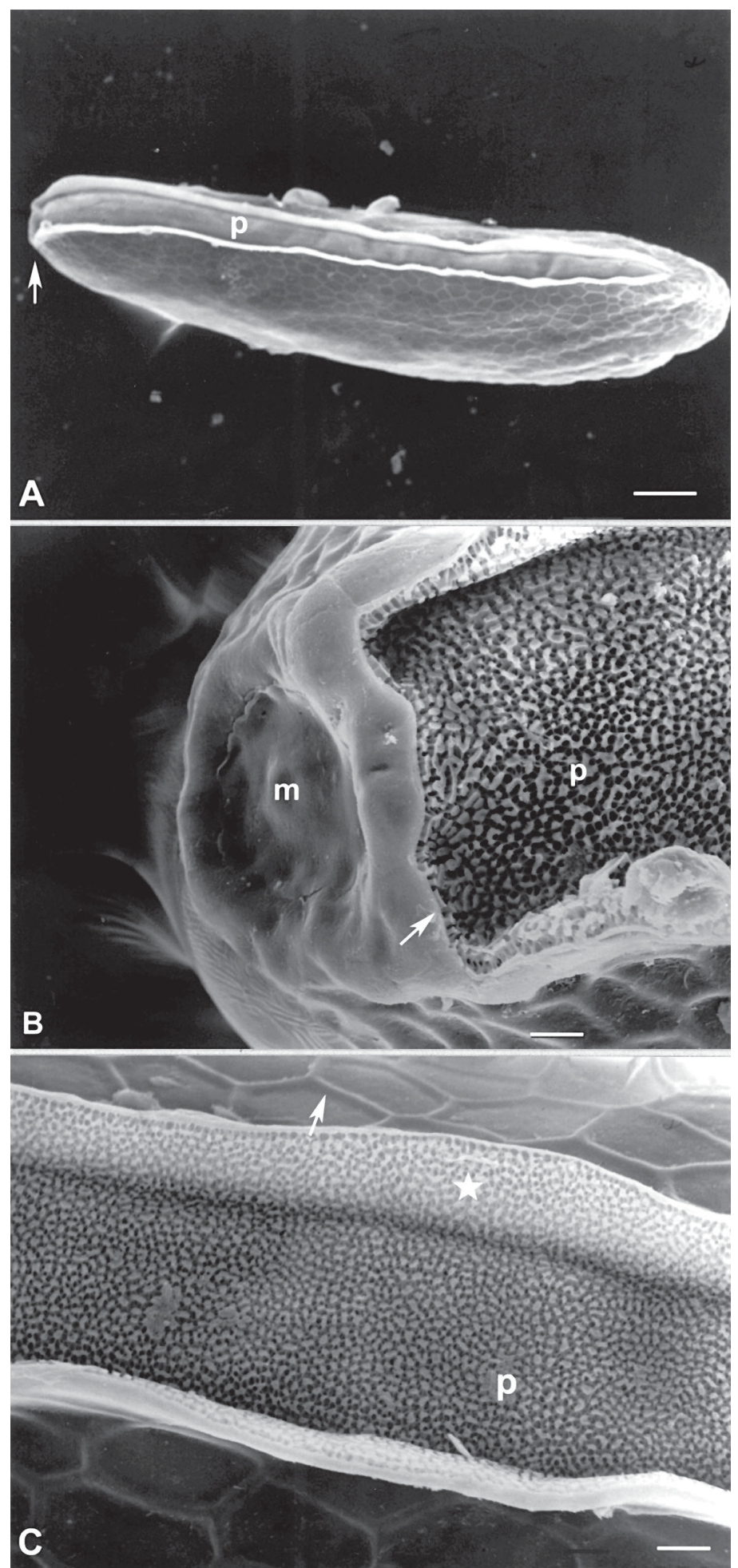

Figure 1. Scanning electron micrographs of the eggshell of Aldrichina grahami (Aldrich). (A) Latero-dorsal view, anterior at left (arrow) and wide plastron area (p) extending to almost the entire length of the egg. Bar $=100 \mu \mathrm{m}$. (B) Plastron near the micropyle showing a truncated shape without bifurcations (arrow). Bar $=10 \mu \mathrm{m}$. (C) Chorionic sculpture showing polygonal patterns bearing a swelling of the boundary (arrow). Plastron (p) is wide and upright (star). Bar $=10 \mu \mathrm{m}$. 

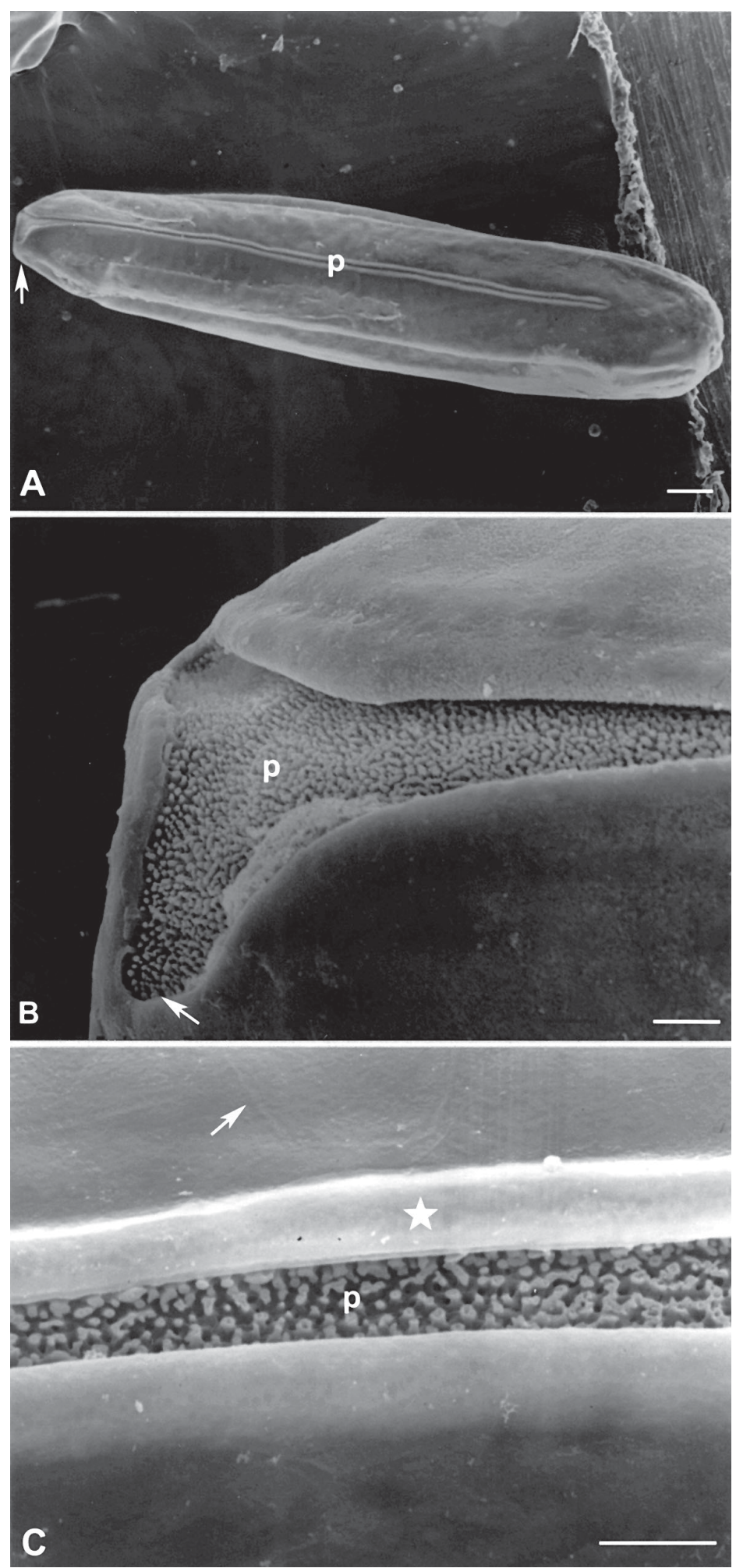

Figure 2. Scanning electron micrographs of the eggshell of Chrysomya pacifica Kurahashi. (A) Dorsal view, anterior at left (arrow) and narrow plastron area (p). Bar $=100 \mu \mathrm{m}$. (B) Plastron (p) near the micropyle showing bifurcation, but arms of the "Y" are short (arrow). Bar $=10 \mu \mathrm{m}$. (C) Smooth and swollen (star) hatching line along the plastron area. Faint polygonal lines (arrow). Bar $=10 \mu \mathrm{m}$. 
and extended plastron area of $C$. pacifica resembles that of many other species of blowflies (e.g. $C$. megacephala, $C$. rufifacies, $C$. albiceps (Wiedemann), $C$. chloropyga (Wiedemann), C. varipes (Macquart), C. saffranea (Bigot) and Cochliomyia macellaria (F.) (Kitching, 1976; Greenberg and Kunich, 2002). Other biological information on $C$. pacifica is little known at present.

The present study adds to the database of eggs of blowfly species that could be of forensic importance in the future. More research on the bionomics of $A$. grahami and $C$. pacifica would then be needed.

\section{ACKNOWLEDGEMENTS}

This study was funded by the Faculty of Medicine Endowment Fund for Medical Research, Faculty of Medicine, Chiang Mai University.

\section{REFERENCES}

ERZINCLIOĞLU YZ (1989) The value of chorionic structure and size in the diagnosis of blowfly eggs. Med Vet Entomol 3: 281-285

GOFF ML (2000) A fly for the prosecution. How insect evidence helps solve crimes. Cambridge, MA: Harvard University Press

GREENBERG B, KUNICH JC (2002) Entomology and the law. Flies as forensic indicators. Cambridge, UK: Cambridge University Press
GREENBERG B, SINGH D (1995) Species identification of calliphorid (Diptera) eggs. J Med Entomol 32: 21-26

GREENBERG B, SZYSKA ML (1984) Immature stages and biology of fifteen species of Peruvian Calliphoridae (Diptera). Ann Entomol Soc Am 77: 488-517

HALL DG (1948) The blowflies of North America. Washington: Thomas Say Foundation

HARDY DE (1981) Insect of Hawaii, Vol. 14, Diptera; Cyclorrhapha IV. Honolulu: The University Press of Hawaii

KITCHING RL (1976) The immature stages of the OldWorld screw-worm fly, Chrysomya bezziana Villeneuve, with comparative notes on other Australasian species of Chrysomya. Bull Entomol Res 66: 195-203

KURAHASHI H, KAWAI S, SHUDO C, WADA Y (1984) Seasonal prevalence of adult fly and life cycle of Aldrichina grahami (Aldrich) in Tokyo. Jpn J Sanit Zool 35: 261-267

KURAHASHI H, CHOWANADISAI L (2001) Blow flies (Insecta: Diptera: Calliphoridae) from Indochina. Species Divers 6: 185-242

LIU D, GREENBERG B (1989) Immature stages of some flies of forensic importance. Ann Entomol Soc Am 82: 80-93

LORD WD (1990) Case histories of the use of insects in investigations. In: CATTS EP, HASKELL NH (eds) Entomology \& Death: A Procedural Guide. South Carolina: Joyce's Print Shop. pp:9-37

MA Y, HU C, MA YK, HU C (1997) A preliminary study on the species and biological characters of necrophagous inects in Hangzhou area. J Zhejiang Agri Univ 23: 375-380

MARGARITIS LH (1985) Structure and physiology of the eggshell. In: KERKUT GA, GILBERT LI (eds) Comprehensive Insect Physiology, Biochemistry and Pharmacology, vol. I. Embryogenesis and Reproduction. New York: Pergamon. pp: 153-230

SHINONAGA S (1965) The altitudinal distribution of flies on Mt. Fuji in summer season. Jpn J Sanit Zool 16: 263-269

SMITH KGV (1986) A Manual of Forensic Entomology. London/Ithaca, NY: British Museum (Natural History)/ Cornell University Press

ZUMPT F (1965) Myiasis in man and animals in the Old World. London: Butterworths 